\title{
The Habits of the Tent-Building Ant (Cremastogaster lineolata
}

Say). William Morton Wheeler. Bull. Amer. Mus. of Nat. Hist., I906, XXII., I-ז8.

In this paper, Dr. Wheeler makes a critical study of C. lineolata's habit of sporadically constructing tents over colonies of aphids and coccids. These tents, which are occasionally constructed by other ants, are composed of agglutinated earth or vegetable detritus. In the words of Dr. Wheeler, "These structures are of local and sporadic occurrence, as if owing their origin to some unusual condition in the environment rather than to the normal instincts of the species." The material for study consisted of several carton tents obtained in the sandy barrens about Lakehurst, New Jersey. The paper contains an excellent historical resumé and numerous excellent illustrations. Indeed the paper contains the first adequate figures of these structures.

As to the possible function of the tents, Dr. Wheeler mentions four suppositions: (I) they prevent the escape of the aphids and coccids to other plants or other parts of the same plant; (2) they protect these insects from their natural enemies or other ants; (3) they protect the aphids and coccids from cold ; (4) they protect the ants from exposure. To the best of my knowledge, Dr. Wheeler is the first scientist to lay stress on the fact that the protection from cold afforded the aphids and coccids by these tents would be of value to the ants; however, he thinks that the main use of these tents is to exclude more powerful competitors for the excreta of the insects. To use his words: "It is not improbable, therefore, that C. lineolata in constructing tents over its charges merely emphasizes its sense of proprietorship in the presence of the larger and more powerful ants with which it has to compete in the struggle for existence; and it may well be that the tents are constructed only in the localities where such competition is unusually severe."

Although the utilitarian value of the tents is manifest and to some they may seem admirable examples of foresight and reason, yet the author is convinced that their construction is due not to intelligence but " to hereditary, instinctive disposition in all colonies of the species, but manifesting itself only under conditions formerly prevalent or universal, but now of rare and sporadic occurrence." The inference that this sporadic tent-building is a reversion to an ancestral habit is supported by the following facts: ( 1 ) in the tropics, many genera live in suspended carton nests; (2) in the tropics, a few species of Cremastogaster live in carton nests; (3) in this latitude, $C$. 
lineolata, in constructing its nests under stones, sometimes uses agglutinated detritus; (4) in at least one instance, $C$. lineolata has been known to construct a carton nest in which the whole colony resided.

C. H. Turner.

The Untuersity of Chicago.

On the Founding of Colonies by Queen Ants, with Special Reference to the Parasitic and Slave-Making Species. William Morton Wheeler. Bull. Amer. Mus. Nat. Hist., 1906, XXII., 33-105.

This paper, an acquaintance with which is indispensable to students of the parasitic and slave-making species of ants, is the result of a large series of experiments made by compelling artificially ' deälated' female ants to consort with small colonies of alien workers. Animal psychologists will be interested to note that some of the conclusions are opposed to certain of Miss Fielde's contentions and to learn that Dr. Wheeler has placed much emphasis upon the then little recognized fact that "the instincts of the ant species have their center of gravity, so to speak, in the female and not, as is usually supposed, in the worker."

In the paper, three methods of founding colonies are discussed; the typical, the redundant, the defective. Typically, the female, unaided, founds a colony and raises her first brood, feeding them by converting her fat-bodies and degenerating wing muscles into food. During this time, the female fasts. In the second case, the female not merely founds, unaided a colony and raises her first brood, but she carries over to that colony and cultivates certain plants which, for countless generations, have been raised by the stock for food. In the third case, the female cannot form a colony unless aided by the workers of some other species.

Under this third or defective method of forming a colony, Dr. Wheeler recognizes three conditions: temporary social parasitism, permanent social parasitism, and dulosis or slavery. Temporary social parasitism is where the female seeks and obtains adoption into a queenless colony and gets those workers to raise her young. When these young have matured, they emancipate themselves from their hosts. This emancipation is secured either through the death of the host species or the emigration of the guest species. Permanent social parasitism begins in the same manner as temporary social parasitism, but the guest species and the host species continue to dwell together as one colony. Dulosis begins in a different manner. A solitary 